\title{
REPERTORIO BIBLIOGRÁFICO
}





\title{
REPERTORIO BIBLIOGRÁFICO SOBRE EL DERECHO DE EXCEPCIÓN ESPAÑOL EN PERSPECTIVA CONSTITUCIONAL
}

\author{
ALICIA GONZÁLEZ MORO \\ Contratada predoctoral FPU \\ Universidad de Sevilla
}

TRC, n. ${ }^{\circ} 48,2021$, pp. 561-589

ISSN 1139-5583

\begin{abstract}
SUMARIO
I. Nota preliminar. II. El marco normativo del derecho de excepción en España. 1. Cuestiones generales. 2. El derecho de excepción como instrumento para afrontar la pandemia de la COVID-19. III. Derechos fundamentales y derecho de excepción. 1. Limitación y suspensión de los derechos fundamentales. 2. El impacto de la pandemia de la COVID-19 en los derechos fundamentales. IV. Funcionamiento de las instituciones y distribución territorial del poder político bajo la vigencia del derecho de excepción. V. El derecho de excepción en clave internacional y comparada.
\end{abstract}

\section{NOTA PRELIMINAR}

El éxito del Estado constitucional como forma avanzada de organización social se debe, en buena medida, a la razón de ser de los propios textos constitucionales. Tal y como sostiene el profesor Pérez Royo, el propósito de una constitución no es otro que la construcción normativa del orden político sustentada en tres principios: la igualdad, la libertad y la seguridad. En este sentido, las previsiones constitucionales definen un estándar de «normalidad social» y el cumplimiento regular de las mismas posibilita la convivencia pacífica de una determinada comunidad política. Sin embargo, es inevitable que los Estados terminen enfrentándose a situaciones de «anormalidad constitucional», esto es, perturbaciones en el orden social que pueden ser de muy diverso calado y que pueden tener su origen en causas muy diferentes. Para hacer frente a estas circunstancias anómalas 
sin abandonar el marco general de convivencia, muchas constituciones optan por prever entre sus páginas algún mecanismo de reacción del Estado, bien en forma de cláusula genérica, o bien detallando los resortes jurídicos que se han de activar para afrontar diversos escenarios excepcionales. Esta respuesta del ordenamiento es lo que se conoce como derecho de excepción o derecho de necesidad.

Así pues, el derecho de excepción opera únicamente en situaciones de crisis desplazando las normas ordinarias de derecho común y fortaleciendo, mediante poderes extraordinarios, la capacidad de actuación del Ejecutivo con el fin de retornar lo antes posible a la normalidad constitucional. Ante supuestos de hecho cuyas consecuencias difícilmente se pueden predecir o anticipar, estas disposiciones normativas deben ofrecer seguridad jurídica y respuestas eficaces; ahora bien, en el marco del constitucionalismo democrático, el derecho de necesidad debe actuar como muro de contención, no sólo de la magnitud de la crisis que amenaza al Estado, sino de cualquier abuso o arbitrariedad por parte de unos poderes públicos que resultan temporalmente robustecidos debido a las excepcionales circunstancias. Estamos, por tanto, ante lo que debe ser una herramienta de defensa política del orden constitucional capaz de garantizar la eficacia de la norma fundamental en cualquier escenario, independientemente de lo grave e incierto que éste sea.

El constituyente español apostó por un modelo de constitucionalización más o menos exhaustiva de las situaciones de anormalidad, prefigurando en el art. 116 CE tres tipos de estados de emergencia —alarma, excepción y sitio- y remitiendo al legislador orgánico para el desarrollo de los mismos. A este respecto, y partiendo de la máxima de que lo previsto como excepción debe operar de manera excepcional, puede sostenerse que el modelo ha funcionado razonablemente bien. Durante cuatro décadas de vigencia del actual régimen constitucional (19782018), el Derecho de excepción tan sólo ha sido aplicado en una ocasión para hacer frente a los estragos ocasionados por la huelga de controladores aéreos del año 2010, cuyo masivo seguimiento provocó el cierre del espacio aéreo y el colapso de las torres de control de un buen número de aeropuertos del país. Cabe apuntar que la declaración de este estado de alarma despertó una fuerte controversia política y doctrinal sobre su pertinencia. Preocupaba estar creando un precedente que aplicase «con ligereza» el derecho de necesidad, lo que demuestra el alto grado de conciencia en torno a la absoluta excepcionalidad que debe caracterizar la declaración de un estado de emergencia.

Lamentablemente, en el escaso margen de una década, nuestro país se ha vuelto a ver inmerso en un escenario de anormalidad constitucional que ha obligado a aplicar — esta vez con muchas menos dudas- el derecho de excepción. La rápida propagación del virus SRAS-CoV-2 durante la primera quincena del mes de marzo de 2020 constató la insuficiencia de las medidas de contención reforzada que, hasta ese momento, habían sido adoptadas para frenar los contagios en el marco del derecho ordinario; por este motivo, el 14 de marzo el Consejo de Ministros aprobó la inmediata entrada en vigor del Real Decreto 463/2020 y 
declaró el estado de alarma en todo el territorio español para gestionar la situación de crisis sanitaria ocasionada por la COVID-19. Este primer estado de alarma concluyó el 21 de junio de 2020, sucediéndole un segundo estado de alarma en octubre circunscrito a nueve municipios de la Comunidad Autónoma de Madrid, y un tercero vigente en todo el territorio nacional que dio comienzo el 25 de octubre y se prolongó hasta el 9 de mayo de 2021.

El repaso a la cronología de los estados de alarma que se han declarado en España me sirve de pretexto para realizar una primera apreciación sobre nuestra producción científica en la materia. Basta una rápida aproximación bibliográfica para comprobar que, pese a tratarse de un asunto de indudable interés en tanto que herramienta de protección del sistema constitucional, lo cierto es que el derecho de excepción no ha sido objeto de un estudio profuso por parte de nuestra doctrina hasta el advenimiento de la pandemia. Las investigaciones sobre cuestiones generales del derecho de necesidad, e incluso sobre los pormenores del polémico estado de alarma del año 2010, resultan llamativamente escasas. Sin embargo, esta situación cambia radicalmente a partir del año 2020. La pandemia se ha convertido en un fenómeno que ha trastocado por completo nuestras vidas, por lo que era de esperar que su trascendencia también monopolizase las contribuciones académicas de los últimos dos años. Teniendo en cuenta el notable vacío doctrinal que había hasta ese momento, es una buena noticia que se haya retomado esta línea de investigación para poner de relieve, por ejemplo, la posible obsolescencia de la normativa de desarrollo o la necesidad de clarificar el régimen de suspensión y limitación de los derechos fundamentales. Sólo queda esperar que el interés no decaiga tras la superación de la crisis sanitaria, pues sería deseable encontrar, en un futuro próximo, estudios desprovistos de los condicionamientos y urgencias actuales para alcanzar conclusiones más sosegadas y, por ende, más reflexivas. En cualquier caso, no cabe duda de que este es el mejor momento para publicar un monográfico sobre derecho de excepción y, a través del presente repertorio, dar buena cuenta de las publicaciones científicas sobre la materia, esperando que el benévolo lector sepa perdonar las posibles carencias y omisiones involuntarias que pudieran detectarse.

La elaboración de un repertorio bibliográfico es un encargo que requiere de un ejercicio metodológico complejo y minucioso; por este motivo, creo que es conveniente dar a conocer los criterios empleados para la selección y clasificación de la bibliografía existente. Por razones de espacio y coherencia interna con el propósito de este monográfico, me he limitado a reflejar las obras que se centran en cuestiones de índole constitucional. Así pues, quedan fuera de este repertorio las interesantes investigaciones desarrolladas en otras áreas del Derecho Público, particularmente en el ámbito del Derecho Administrativo, a cuya lectura y consulta me remito para obtener una visión aún más completa de este objeto de estudio. Por lo que respecta a la justificación taxonómica, las contribuciones académicas han sido clasificadas en cuatro grandes categorías que parten de una panorámica general sobre la normativa de excepción para, posteriormente, 
prestar atención al impacto en los derechos fundamentales, analizar la repercusión en el funcionamiento de las instituciones políticas e incorporar la perspectiva comparada.

La primera categoría engloba los trabajos sobre el marco normativo del derecho de excepción en España, es decir, aquellos que reflexionan sobre el concepto de «necesidad» y analizan de manera pormenorizada tanto el contenido del artículo 116 CE, como su posterior desarrollo en la Ley Orgánica 4/1981, de 1 de junio, de los Estados de Alarma, Excepción y Sitio (LOEAES). Esta aproximación general a la regulación de los estados de emergencia se acompaña de un apartado específico donde aparecen desglosadas las publicaciones que han estudiado el derecho de excepción como herramienta de gestión de la crisis provocada por la COVID-19, examinando su aplicabilidad en situaciones de grave emergencia sanitaria, destacando sus fortalezas y criticando sus debilidades.

La siguiente categoría hace referencia al que, probablemente, ha sido el gran debate jurídico-constitucional derivado de la pandemia: la incidencia en los derechos fundamentales de las medidas adoptadas por las autoridades para contener el avance del virus. Dentro de este grupo, he decidido destinar un primer epígrafe a los trabajos sobre teoría general de los derechos fundamentales que analizan los fenómenos de la limitación y la suspensión de derechos según lo dispuesto en la Constitución Española y en el Convenio Europeo de Derechos Humanos. El art. 55.1 CE prevé la posibilidad de suspender ciertos derechos — recogidos en una enumeración taxativa- cuando se declara un estado de excepción o un estado de sitio; es por ello que medidas como el confinamiento general de la población decretado bajo el estado de alarma de marzo de 2020 pusieron de relieve la necesidad de clarificar los criterios que determinan si un derecho sólo ha sido restringido de forma severa, o si directamente ha quedado en suspenso, ya que de esta valoración puede depender la adecuación constitucional de un estado de emergencia. Las profundas discrepancias jurídicas sobre este asunto finalmente han quedado reflejadas en el fallo y en los cinco votos particulares discrepantes de la esperada STC 148/2021, de 14 de julio, donde una ajustadísima mayoría concluyó que bajo el primer estado de alarma quedaron en suspenso las libertades de circulación y residencia. Por su parte, el segundo epígrafe se centra en el examen de las condiciones de ejercicio y la tutela de diversos derechos fundamentales bajo el estado de alarma sanitaria, pudiendo encontrar investigaciones específicas sobre la libertad de circulación, el derecho de reunión, la intimidad y el derecho a la salud, entre otros.

En tercer lugar, se desglosa un elenco de contribuciones que versan sobre el funcionamiento de las instituciones y la distribución territorial del poder político en el marco de los estados de emergencia, cuestión sobre la que el Tribunal Constitucional previsiblemente se pronunciará en la sentencia derivada de la impugnación del último estado de alarma. La práctica totalidad de los trabajos que integran esta categoría también responde a la coyuntura originada por la crisis sanitaria; no en vano, se trata de la emergencia constitucional que más se ha prolongado en el tiempo y, por tanto, la que más ha podido influir en las dinámicas institucionales y 
de cogobernanza en nuestro país. La doctrina ha prestado especial atención al desarrollo de la actividad parlamentaria bajo el estado de alarma — virtualidad de los mecanismos de control al gobierno, producción normativa, implementación del voto telemático y demás adaptaciones tecnológicas de la labor de representación política, etc.- - pero también ha tenido ocasión de analizar la celebración de comicios electorales en tiempos de pandemia y las posibilidades de control jurisdiccional de las medidas adoptadas para frenar el avance del virus. Asimismo, resultan fundamentales las publicaciones que examinan la gestión de la crisis sanitaria en clave territorial, tratando de desenmarañar el lío competencial para establecer mecanismos de coordinación entre los distintos niveles de gobierno, imputar responsabilidades y facilitar los ejercicios de rendición de cuentas.

El repertorio se cierra con un apartado final que recoge la perspectiva comparada del derecho de excepción. Alzar la mirada a Europa, pero también a otras latitudes que nos resultan tan próximas como sucede con América Latina, es una labor imprescindible si queremos realizar un buen análisis de las diversas respuestas jurídicas que se han articulado para gestionar la crisis sanitaria de la COVID-19. Puesto que la pandemia se ha revelado como un auténtico fenómeno global, resulta de interés conocer las iniciativas impulsadas por la Unión Europea, los posicionamientos de la Comisión de Venecia y el régimen jurídico de los poderes de emergencia en otros países de nuestro entorno. El listado de obras en este apartado podría ser infinito; por ello, me he limitado a seleccionar contribuciones escritas en castellano y publicadas en nuestro país que analizan experiencias europeas e iberoamericanas y que, o bien realizan estudios comparativos, o bien se insertan en obras colectivas y monográficos destinados a aportar una visión internacional del objeto de estudio que nos ocupa.

No me gustaría finalizar esta breve nota preliminar sin traer a colación las palabras del profesor Cruz Villalón, publicadas en una tribuna de opinión del periódico El País durante la vigencia del primer estado de alarma por emergencia sanitaria. En su artículo titulado «La Constitución bajo el estado de alarma» advertía que, si bien había resultado imprescindible poner nuestra norma fundamental al servicio de la lucha contra el virus, corríamos «el riesgo de olvidar que la propia Constitución es también un valor básico en sí mismo considerado, y que también él puede salir dañado en la presente situación de emergencia». En este sentido, quienes estudiamos e investigamos sobre Derecho Constitucional hemos tenido que asumir una cuota importante de responsabilidad durante esta crisis. $\mathrm{Al}$ igual que la medicina no ha dudado en destinar todos sus esfuerzos al desarrollo de fármacos y vacunas para neutralizar el avance y los perniciosos efectos del virus, la doctrina jurídico-constitucional se ha volcado en la labor de vigilancia de la actuación del poder político, ha examinado el encaje normativo de las medidas adoptadas, ha analizado su incidencia en los derechos fundamentales, ha supervisado el funcionamiento de nuestras instituciones y ha formulado propuestas de lege ferenda. Creo, sin lugar a dudas, que el presente elenco bibliográfico $-\mathrm{y}$ los debates de interés público que subyacen en él- constituyen una buena muestra de ese loable 
compromiso con la salvaguarda de los principios de nuestro Estado social y democrático de Derecho. Una labor que deviene aún más necesaria, si cabe, en los periodos de excepcionalidad constitucional, donde se pone a prueba la resistencia de los cimientos básicos de nuestro orden político.

\section{EL MARCO NORMATIVO DEL DERECHO DE EXCEPCIÓN EN ESPAÑA}

\section{Cuestiones generales}

\section{Libros y capitulos de libros}

Agamben, G., Estado de excepción. Homo sacer II, 1, Pre-Textos, Valencia, 2004.

Álvarez García, V. J., El concepto de necesidad en Derecho Público, Tesis doctoral, Universidad de Alcalá, 1994.

Arroyo, Gil, A., «La naturaleza del estado de alarma y su presupuesto habilitante», GARrido López, C. (coord.), Excepcionalidad y derecho: el estado de alarma en España, Colección Obras Colectivas, Fundación Manuel Giménez Abad, Zaragoza, 2021.

Carro Martínez, A., "Artículo 116. Situaciones de anormalidad constitucional», Alzaga Villaamil, O. (dir.), Comentarios a la Constitución Española de 1978, Tomo IX, Cortes Generales, Editoriales de Derecho Reunidas, Madrid, 1996.

Cruz Villalón, P., El estado de sitio y la Constitución. La constitucionalización de la protección extraordinaria del Estado (1789-1878), Centro de Estudios Constitucionales, Madrid, 1980.

- Estados excepcionales y suspensión de garantías, Tecnos, Madrid, 1984.

Duque Villanueva, J. C., «Artículo 116», Pérez Tremps, P y SÁiz Arnáiz, A. (dirs.), Comentario a la Constitución Española: 40 aniversario 1978-2018. Libro-bomenaje a Luis López Guerra, vol. 1, Tirant Lo Blanch, Valencia, 2018.

Fernández de Casadevante Mayordomo, P., «La crisis de los controladores aéreos y la Covid-19 como emergencias constitucionales insuficientemente regladas. Propuestas «de lege ferenda» para el estado de alarma», GARrido López, C. (coord.), Excepcionalidad y derecho: el estado de alarma en España, Colección Obras Colectivas, Fundación Manuel Giménez Abad, Zaragoza, 2021.

L La defensa de la Constitución. El derecho de emergencia constitucional y el artículo 55 CE, Thomson Reuters-Aranzadi, Cizur Menor, 2020.

Fernández Segado, F., El estado de excepción en el Derecho Constitucional español, Edersa, Madrid, 1978.

GARrido López, C., «El problema de la justiciabilidad de los decretos de declaración y de prórroga del estado de alarma», GARrido López, C. (coord.), Excepcionalidad y derecho: el estado de alarma en España, Colección Obras Colectivas, Fundación Manuel Giménez Abad, Zaragoza, 2021.

- «Las limitaciones como derecho del Derecho constitucional de excepción», GARrido López, C. (coord.), Excepcionalidad y derecho: el estado de alarma en España, Colección Obras Colectivas, Fundación Manuel Giménez Abad, Zaragoza, 2021. 
«Sobre la naturaleza jurídica de la declaración de los estados excepcionales previstos en el art. 116 de la CE y su control jurisdiccional», VV. AA., Estudios sobre la Constitución Española: homenaje al profesor Jordi Solé Tura, vol. 2, Cortes Generales y Centro de Estudios Políticos y Constitucionales, Madrid, 2008.

Lecumberri Beascoa, G., El Derecho de excepción: una perspectiva de Derecho comparado. España: estado de alarma, EPRS: Servicio de Estudios del Parlamento Europeo, Bruselas, 2020.

López UlLa, J. M., «La defensa de la Constitución: jurisdicción constitucional, reforma y estados excepcionales», VV. AA., Manual de Derecho Constitucional, 12. ${ }^{a}$ ed., Tecnos, Madrid, 2021.

Mateu-Ros y Cerezo, R., «Estados de alarma, excepción y sitio», VV. AA., Gobierno y Administración en la Constitución, vol. I, Instituto de Estudios Fiscales, Madrid, 1988.

Pérez Royo, J. y Carrasco Durán, M., Curso de Derecho Constitucional, 16. a ed., Marcial Pons, Madrid, 2018.

Presno Linera, M. Á., «Estado de alarma y sociedad del riesgo global», Atienza Macías, E. y Rodríguez Ayuso, J. F. (dirs.), Las respuestas del derecho a las crisis de salud pública, Dykinson, Madrid, 2020.

REQuejo Rodríguez, P., «Teoría vs. práctica del estado de alarma en España», VV. AA. Constitución y democracia: ayer y hoy. Libro bomenaje a Antonio Torres del Moral, vol. 2, Universitas, 2012.

Serrano Alberca, J. M., «Artículo 116», Garrido Falla, F. (dir.), Comentarios a la Constitución, Civitas, Madrid, 1985.

«Situaciones excepcionales y fuentes del derecho en la Constitución española de 1978», VV. AA., La Constitución española y las fuentes del derecho, vol. III, Instituto de Estudios Fiscales, Madrid, 1979.

SolozÁbal Echavarría, J. J., «Algunas consideraciones constitucionales sobre el estado de alarma», Biglino Campos, P. y Durán Alba, J. F. (dirs.), Los efectos horizontales de la Covid-19 sobre el sistema constitucional: estudios sobre la primera oleada, Colección Obras Colectivas, Fundación Manuel Giménez Abad, Zaragoza, 2021.

Torre de Silva y López de Letona, J., «La ley y el Estado de Alarma: el desplazamiento temporal de normas», Recuerda Girela, M. Á. (coord.), Antes de la próxima pandemia, Thomson Reuters-Aranzadi, Cizur Menor, 2020.

VAladÉs, D., «Introducción. Problemas constitucionales de los estados de emergencia», Barceló Rojas, D., Díaz Ricci, S., García Roca, J. y Guimaráes Teixeira RocHA, M. E., (coords.), COVID 19 y parlamentarismo. Los Parlamentos en cuarentena, Instituto de Investigaciones Jurídicas. Universidad Nacional Autónoma de México, México, 2020.

Vera Santos, J. M., «Secesión y derecho de excepción. A vueltas con el estado de alarma en España», Fernández de Casadevante Romani, C., Consecuencias jurídicas de la secesión de entidades territoriales. Una visión para España, Aranzadi, Navarra, 2020.

Artículos de revistas

Aва Catoira, A., «El estado de alarma en España», Teoría y Realidad Constitucional, n. ${ }^{\circ} 28,2011$, pp. 305-334. 
Alcubilla, E. A., «El estado de alarma al descubierto», Derecho Global. Estudios sobre Derecho y Justicia, n. ${ }^{\circ}$ 16, 2020, pp. 227-236.

Álvarez García, F. J., «Estado de alarma o de excepción», Estudios Penales y Criminológicos, n. ${ }^{\circ}$ 40, 2020, pp. 1-20.

Álvarez VÉlez, M. I., «Sistema de fuentes del Derecho y estado de alarma: la STC 83/2016, de 28 de abril», Asamblea: Revista parlamentaria de la Asamblea de Madrid, n. ${ }^{\circ} 34,2016$, pp. 325-340.

Bru Peral, E. M., «Estados de alarma, excepción y sitio», Derechos y libertades: Revista de Filosofía del Derecho y derechos bumanos, n. ${ }^{\circ}$ 7, 1999, pp. 141-188.

Calderón Cerezo, Á., «Derecho constitucional de excepción y Estado de Alarma», Diario La Ley, n. ${ }^{\circ}$ 9789, 2021.

Cruz Villalón, P., «El nuevo Derecho de Excepción (Ley Orgánica 4/1981, de 1 de junio)», Revista Española de Derecho Constitucional, vol. 1, n. ${ }^{\circ}$ 2, 1981, pp. 93-128.

- -Entre proporcionalidad e identidad: las claves de la excepcionalidad en el momento actual», Revista de Derecho Constitucional Europeo, n. . 27, 2017, pp. 1-12.

— «ormalidad y excepción», Revista Española de Derecho Constitucional, n. ${ }^{\circ} 71$, 2004, pp. 187-200.

- «Veinticinco años de normalidad constitucional», Revista de Derecho Político, n. ${ }^{\text {os }}$ 58-59, 2003-2004, pp. 17-27.

Espín López. I., «Estado de alarma en el sistema constitucional español: espacio aéreo», Revista Acta Judicial, n. ${ }^{\circ}$ 2, 2018, pp. 115-131.

Fernández de Casadevante Mayordomo, P., «El derecho de emergencia constitucional en España: hacia una nueva taxonomía», Revista de Derecho Político, n. ${ }^{\circ} 107$, 2020, pp. 111-145.

FERnÁndez Segado, F., «La Ley Orgánica de los Estados de Alarma, Excepción y Sitio», Revista de Derecho Político, n. ${ }^{\circ} 11,1981$, pp. 83-116.

García CuAdrado, A. M., "Aproximación a una teoría de los "actos constitucionales”", Revista de Derecho Político, n. ${ }^{\circ} 46,1999$, pp. 39-104.

—El estado de alarma y su ambigua naturaleza», Cuadernos Constitucionales de la Cátedra Fadrique Furió Ceriol, n. . 8, 1994, pp. 75-107.

GARRIDO López, C., «Naturaleza jurídica y control jurisdiccional de las decisiones constitucionales de excepción», Revista Española de Derecho Constitucional, n. ${ }^{\circ} 110,2017$, pp. 43-73.

— «Sobre el estado de sitio, su régimen jurídico y el control jurisdiccional de su declaración», Revista de Derecho Político, n. ${ }^{\circ}$ 68, 2007, pp. 107-142.

Goig Martínez, J. M., «Defensa política de la Constitución. Emergencia, excepcionalidad y democracia», Cuestiones Jurídicas, vol. VIII, n. ${ }^{\circ}$ 2, 2014, pp. 11-39.

—La defensa política de la Constitución. Constitución y estados excepcionales (I)», Revista de Derecho UNED, n. ${ }^{\circ}$ 4, 2009, pp. 263-296.

GONZÁlEz LóPEZ, J. J., «Reales decretos de declaración y prórroga del estado de alarma», Gabilex: Revista del Gabinete Jurídico de Castilla-La Mancha, n. ${ }^{\circ}$ 21, 2020, pp. 109-132.

Higuera Guimerá, J.F., «Los estados de alarma, excepción y sitio, y el código penal militar de 1985», Revista General de Derecho Penal, n. . 15, 2011, pp. 1-65.

LAfuente Balle, J. M., «Los estados de alarma, excepción y sitio (II)», Revista de Derecho Político, n. ${ }^{\circ} 31,1990$, pp. 27-68. 
«Los estados de alarma, excepción y sitio», Revista de Derecho Político, n. ${ }^{\circ}$ 30, 1989, pp. 23-54.

Navas Castillo, A., «Los Estados excepcionales y su posible control por el Tribunal Constitucional», Revista de la Facultad de Derecho de la Universidad Complutense, n. ${ }^{\circ} 87,1997$, pp. 133-164.

Porres Azkona, J., «La decisión sobre poderes excepcionales», Revista Vasca de Administración Pública, n. ${ }^{\circ}$ 6, 1983, pp. 9-72.

— «a defensa extraordinaria del Estado», Revista de Estudios Políticos, n. ${ }^{\circ}$ 216, 1977, pp. 141-180.

Santaolalla López, F., «Crónica Parlamentaria», Revista Española de Derecho Constitucional, vol. I, n. ${ }^{\circ} 2,1981$, pp. 249-282.

Sieira Mucientes, S., «Estado de alarma», Eunomía. Revista en Cultura de la Legalidad, n. ${ }^{\circ} 19,2020$, pp. 275-305.

Troper, M., «El estado de excepción no tiene nada de excepcional», Revista de Derecho Constitucional Europeo, n. ${ }^{\circ}$ 27, 2017, pp. 193-204.

Vidal Prado, C. y Delgado Ramos, D., «Algunas consideraciones sobre la declaración del Estado de alarma y su prórroga», Revista Española de Derecho Constitucional, n. ${ }^{\circ}$ 92, 2011, pp. 243-265.

\section{El derecho de excepción como instrumento para afrontar la pandemia de la COVID-19}

Libros y capitulos de libros

Aguado Renedo, C., «La incidencia de la pandemia en el sistema constitucional español», Aragón Reyes, M., Cossío Díaz, J. R. y Nava Gomar, L. F. (coords.), La crisis del parlamentarismo en nuestra democracia constitucional, Tirant Lo Blanch, Valencia, 2021.

Álvarez García, V., Arias Aparicio, F. y Hernández Díez, E., Lecciones jurídicas para la lucha contra una epidemia, Iustel, Madrid, 2020.

Atienza Macías, E. y Rodríguez Ayuso, J. F. (dirs.), Las respuestas del derecho a las crisis de salud pública, Dykinson, Madrid, 2020.

Biglino Campos, P. y Durán Alba, J. F. (dirs.), Los efectos horizontales de la Covid-19 sobre el sistema constitucional: estudios sobre la primera oleada, Colección Obras Colectivas, Fundación Manuel Giménez Abad, Zaragoza, 2021.

Blanquer Criado, D. V. (coord.), COVID-19 y Derecho Público (durante el estado de alarma y más allá), Tirant Lo Blanch, Valencia, 2020.

Cabanas Veiga, M., «El derecho de excepcionalidad español ante futuras pandemias», Dueñas Castrillo, A. I., Fernández Cañueto, D., Guerrero Vázquez, P. y Moreno GonzÁlez, G. (coords.), La Constitución en tiempos de pandemia, Dykinson, Madrid, 2021.

Canosa Usera, R., «Ordenación de las fuentes del derecho en estados de emergencia sanitaria. El caso español», Barceló Rojas, D., Díaz Ricci, S., García Roca, J. y Guimaráes Teixeira Rocha, M. E., (coords.), COVID 19 y parlamentarismo. Los 
Parlamentos en cuarentena, Instituto de Investigaciones Jurídicas. Universidad Nacional Autónoma de México, México, 2020.

Carmona Contreras, A. M., «El estado de alarma y la emergencia sanitaria Covid-19: Un análisis desde la perspectiva constitucional», GómEZ MUÑOZ, J. M. (ed.) y Rodríguez Ramos, M. J. (coord.), Nuevos escenarios del sistema de relaciones laborales derivados del COVID-19, Bomarzo, Albacete, 2021.

Cossío Díaz, J. R., «Constitucionalismo y pandemia», Aragón Reyes, M., Cossío Díaz, J. R. y Nava Gomar, L. F. (coords.), La crisis del parlamentarismo en nuestra democracia constitucional, Tirant Lo Blanch, Valencia, 2021.

Cuenca Miranda, A., "Análisis crítico de un estado de alarma excepcional: la Covid19 y el derecho de excepción», GARrido López, C. (coord.), Excepcionalidad y derecho: el estado de alarma en España, Colección Obras Colectivas, Fundación Manuel Giménez Abad, Zaragoza, 2021.

Dueñas Castrillo, A. I., Fernández Cañueto, D., Guerrero Vázquez, P. y Moreno GonzÁlez, G. (coords.), La Constitución en tiempos de pandemia, Dykinson, Madrid, 2021.

Fernández de Casadevante Mayordomo, P., «Desafíos constitucionales ante el coronavirus», Cobo del Rosal Pérez, G. (dir.) y Navalpotro Sánchez-PeiNADO, J. M., (ed. lit.), Derechos fundamentales en estado de alarma: una aproximación multidisciplinar, Dykinson, 2020.

Fernández Rodríguez, T. R., «El Estado de Derecho, a prueba», Blanquer Criado, D. V. (coord.), COVID-19 y Derecho Público (durante el estado de alarma y más allá), Tirant Lo Blanch, Valencia, 2020.

GonZÁlez Martín, N. y VAladÉs, D. (coords.), Emergencia sanitaria por Covid 19. Derecho Constitucional comparado, Universidad Nacional Autónoma de México, México, 2020.

Mori VAra, P., «El estado de alarma: su justificación desde el punto de vista de la salud pública», Cobo del Rosal Pérez, G. (dir.) y Navalpotro Sánchez-Peinado, J. M., (ed. lit.), Derechos fundamentales en estado de alarma: una aproximación multidisciplinar, Dykinson, 2020.

Navalpotro SÁnchez-Peinado, J. M., «Normas excepcionales en tiempos de calamidades sanitarias: constantes en el pasado», CoBo Del Rosal PÉrez, G. (dir.) y Navalpotro Sánchez-Peinado, J. M., (ed. lit.), Derechos fundamentales en estado de alarma: una aproximación multidisciplinar, Dykinson, 2020.

Pendás, B. (ed.), Enciclopedia de las Ciencias morales y políticas para el siglo XXI. Ciencias Políticas y Jurídicas (con especial referencia a la sociedad pos-Covid-19), Real Academia de Ciencias Morales y Políticas y Boletín Oficial del Estado, Madrid, 2020.

Pomed SÁnchez, L., «Algunas notas sobre los estados de alarma declarados en 2020», Tudela Aranda, J. (coord.), Estado autonómico y COVID-19: un ensayo de valoración general, Colección Obras colectivas, Fundación Manuel Giménez Abad, Zaragoza, 2021.

Recuerda Girela, M. Á. (coord.), Antes de la próxima pandemia, Thomson Reuters-Aranzadi, Cizur Menor, 2020.

Revenga SÁnCHeZ, M., «Dimensiones constitucionales de la crisis del coronavirus en España: una crónica de urgencia», GonZÁlez MARTín, N. y VAladés, D. (coords.), Emergencia sanitaria por Covid 19. Derecho Constitucional comparado, Universidad Nacional Autónoma de México, México, 2020. 
Rodríguez Ruiz, B., «Democracia y pandemia: ¿nueva normalidad o viejos fantasmas?, Mantilla, J. y Hervas, A. (eds.), COVID-19 ¿Estuvimos listos? Reflexiones académicas ante el Estado, mercado y comunidad, Universidad de Otavalo, 2020.

Artículos de revistas

Alcubilla, E. A., «Los principios que deben regir la lucha contra el Covid-19 en el Estado democrático de Derecho», Diario La Ley, n. ${ }^{\circ}$ 9661, 2020.

Álvarez García, V. J., «El comportamiento del Derecho de crisis durante la segunda ola de la pandemia», El Cronista del Estado Social y Democrático de Derecho, n. ${ }^{\circ}$ 90-91, 2020, pp. 26-41.

—El coronavirus (COVID-19): respuestas jurídicas frente a una situación de emergencia sanitaria», El Cronista del Estado Social y Democrático de Derecho, n. ${ }^{\circ} 86-87$, 2020, pp. 6-21.

Aragón Reyes, M., «Covid-19: aproximación constitucional a una crisis», Revista General de Derecho Constitucional, n. ${ }^{\circ}$ 32, 2020, pp. 1-5.

FERnÁndeZ DE GATTA SÁNCHEZ, D., «El Estado de alarma en España por la epidemia del coronavirus y sus problemas», Revista General de Derecho Constitucional, n. ${ }^{\circ}$ 33, 2020.

FERnÁNDEZ RodrígueZ, J. J., «Cuestiones constitucionales sobre el estado de alarma en España y la pandemia del COVID-19», Boletín IEEE, n. ${ }^{\circ} 18,2020$, pp. 699-720.

Ferrajoli, L., «Lecciones de la pandemia», Jueces para la democracia, n. ${ }^{\circ}$ 98, 2020, pp. 37-40.

Herbón Costas, J. J., «La gestión de las crisis en el marco de la Ley de Seguridad Nacional: la pandemia por COVID-19 y la necesidad de una urgente reforma», Revista Española de Derecho Constitucional, n. ${ }^{\circ} 121,2021$, pp. 139-168.

Lara Ortiz, M. L., «Replanteando la gestión de emergencias sanitarias», Revista Española de Derecho Constitucional, n. ${ }^{\circ} 122,2021$, pp. 153-182.

Nogueira López, A., "Confinar el coronavirus: entre el viejo Derecho sectorial y el Derecho de excepción», El Cronista del Estado Social y Democrático de Derecho, n. ${ }^{\circ} 86-87,2020$, pp. 22-31.

Ruiz Robledo, A., «Problemas constitucionales del estado de alarma por la covid-19 en España», Revista de Estudios Jurídicos UNESP, n. ${ }^{\circ}$ 38, 2021, pp. 83-104.

Teruel Lozano, G. M., «Los decretos-leyes en la crisis del coronavirus: perspectiva constitucional», Cuadernos Manuel Giménez Abad, n. ${ }^{\circ}$ extraordinario 8, 2020, pp. 216-225.

\section{DERECHOS FUNDAMENTALES Y DERECHO DE EXCEPCIÓN}

\section{Limitación y suspensión de los derechos fundamentales}

Libros y capítulos de libros

Acosta Sánchez, J., «Suspensión de derechos y libertades», Jiménez De Parga y Cabrera, M. y Vallespín OÑa, F. (coords.), La Política, Colección España Siglo XXI, Biblioteca Nueva, 2008. 
Aláez Corral, B., «El concepto de suspensión general de los derechos fundamentales», López Guerra, L. M. y Espín Templado, E. (coords.), La defensa del Estado: actas del I Congreso de la Asociación de Constitucionalistas de España, 2004.

Blanco Valdés, R. L., "Artículo 55», Pérez Tremps, P. y Sáiz Arnáiz, A. (dirs.), Comentario a la Constitución Española: 40 aniversario 1978-2018. Libro-bomenaje a Luis López Guerra, vol. 1, Tirant Lo Blanch, Valencia, 2018.

Carrillo, M., «Defensa del Estado y suspensión de derechos: una introducción», López Guerra, L. M. y Espín Templado, E. (coords.), La defensa del Estado: actas del I Congreso de la Asociación de Constitucionalistas de España, 2004.

Díaz Revorio, F. J., «Desactivando conceptos constitucionales: la suspensión de derechos y los estados excepcionales», GARrido López, C. (coord.), Excepcionalidad y derecho: el estado de alarma en España, Colección Obras Colectivas, Fundación Manuel Giménez Abad, Zaragoza, 2021.

FERnÁNDEZ SÁNCHEZ, P. A., «La suspensión de las garantías establecidas en el Convenio Europeo de Derechos Humanos (art. 15)», García Roca, F. J. y SANTOlaya MachetTi, P. (coords.), La Europa de los derechos: el Convenio Europeo de Derechos Humanos, Centro de Estudios Políticos y Constitucionales, Madrid, 2009.

Fernández Segado, F., "Artículo 55: la suspensión de derechos», Alzaga Villaamil, O. (dir.), Comentarios a la Constitución Española de 1978, Tomo IV, Cortes Generales, Editoriales de Derecho Reunidas, Madrid, 1996.

FERnández Silva, Á., «La restricción de los derechos fundamentales durante la crisis sanitaria en España», Dueñas Castrillo, A. I., Fernández Cañueto, D., Guerrero VÁzquez, P. y Moreno González, G. (coords.), La Constitución en tiempos de pandemia, Dykinson, Madrid, 2021.

GARRIDO MAYOL, V., «Limitaciones y suspensiones de derechos: muchos puntos controvertidos», Recuerda Girela, M. Á. (coord.), Antes de la próxima pandemia, Thomson Reuters-Aranzadi, Cizur Menor, 2020.

GómEz FERnÁNDEZ, I., «¿Limitación o suspensión? Una teoría de los límites a los derechos fundamentales para evaluar la adopción de estados excepcionales», GARRIDO López, C. (coord.), Excepcionalidad y derecho: el estado de alarma en España, Colección Obras Colectivas, Fundación Manuel Giménez Abad, Zaragoza, 2021.

GonZÁlez Beilfuss, M., «La suspensión general de derechos», López Guerra, L. M. y Espín Templado, E. (coords.), La defensa del Estado: actas del I Congreso de la Asociación de Constitucionalistas de España, 2004.

Lazkano Brotóns, I. y Lasagabaster Herrarte, I., "Artículo 15. Derogación en caso de urgencia», Lasagabaster Herrarte, I. (dir.), El Convenio Europeo de Derechos Humanos. Comentario sistemático, Thomson Reuters-Civitas, Madrid, 2009.

Martínez Cuevas, D., La suspensión individual de derechos y libertades fundamentales en el ordenamiento constitucional español. Instrumento de defensa de la constitución de 1978, Tesis doctoral, Universidad de Granada, 1998.

Peña Freire, A. M., «Limitaciones y suspensión de los derechos (art. 29.2, 2.3 DUDH; art. 4.1, 5.1, 12.3, 14.1, 18.3, 19.3, 21, 22.2 PIDCP; art. 4, 5.1, 8.1.a), 8.1.c), 8.2 PIDESC)», Monereo Atienza, C. y Monereo Pérez, J. L. (dirs. y coords.), El sistema universal de los derechos humanos. Estudio sistemático de la Declaración Universal de los Derechos Humanos, el Pacto Internacional de Derechos Civiles y Políticos, el Pacto Internacional de Derechos Económicos, Sociales y Culturales y textos internacionales concordantes, Comares, Granada, 2014. 
PÉrez Sola, N., «La suspensión de los derechos fundamentales: los estados excepcionales», Peces-Barba Martínez, G., Fernández García, E., De Asís Roig, R., Ansuátegui Roig, F. J. y Fernández liesa, C. R. (dirs.), Historia de los derechos fundamentales, Tomo IV, Vol. VI, Libro I, Dykinson, Madrid, 2014.

Remotti Carbonell, J. C., La suspensión individual de derechos en la Constitución española de 1978, Universitat Autònoma de Barcelona, Barcelona, 1998.

Requejo Rodríguez, P., «Artículo 55», Casas BaAmonde, M. E. y Rodríguez-PiÑero y Bravo Ferrer, M. (dirs.), Comentarios a la Constitución Española, Boletín Oficial del Estado, Madrid, 2018.

— «La suspensión de los derechos fundamentales», BAstida Freijedo, F. J. et al., Teoría general de los derechos fundamentales en la Constitución española de 1978, Tecnos, Madrid, 2004.

Ruiz Robledo, A., «Los derechos en riesgo: conviene una reforma legal», ReCuerda Girela, M. Á. (coord.), Antes de la próxima pandemia, Thomson Reuters-Aranzadi, Cizur Menor, 2020.

Villaverde MenÉndez, I., «Los límites a los derechos fundamentales», VV.AA., Teoría general de los derechos fundamentales en la Constitución española de 1978, Tecnos, Madrid, 2012.

Artículos de revistas

Aba Catoira, A., «El concepto jurisprudencial de límite de los derechos fundamentales», Anuario da Facultade de Dereito, n. . 2, 1998, pp. 13-31.

Aguiar De LuQue, L., «Los límites de los derechos fundamentales», Revista del Centro de Estudios Constitucionales, n. ${ }^{\circ} 14,1993$, pp. 9-34.

Berdugo Gómez de la Torre, I., «Garantías en la Constitución ante la suspensión de los derechos fundamentales», Sistema: Revista de Ciencias Sociales, n. ${ }^{\circ} 42,1981$, pp. 57-78.

Carrillo López, M., «Derecho de excepción y garantía de los derechos en tiempos de pandemia», Revista del Parlamento Vasco, n. ${ }^{\circ}$ 1, 2020, pp. 60-93.

Cotino Hueso, L., «Los derechos fundamentales en tiempos del coronavirus: Régimen general y garantías y especial atención a las restricciones de excepcionalidad ordinaria», El Cronista del Estado Social y Democrático de Derecho, n. ${ }^{\circ} 86-87,2020$, pp. 88-101.

De La Quadra-Salcedo, T., «La naturaleza de los derechos fundamentales en situaciones de suspensión», Anuario de Derechos Humanos, n. ${ }^{\circ}$ 2, 1983, pp. 428-472.

Escobar Roca, G., «Los derechos humanos en estados excepcionales y el concepto de suspensión de derechos fundamentales», Revista de Derecho Político, n. ${ }^{\circ}$ 110, 2021, pp. 113-152.

Fernández de Casadevante Mayordomo, P., «Los derechos fundamentales en estado de alarma: una suspensión inconstitucional», Revista Vasca de Administración Pública, n. ${ }^{\circ} 119,2021$, pp. 59-99.

FERnÁNDEZ SEGADO, F., «La suspensión de garantías constitucionales en la nueva Constitución española», Revista de Estudios Políticos, n. ${ }^{\circ}$ 7, 1979, pp. 299-312.

—La suspensión individual del ejercicio de derechos constitucionales», Revista de Estudios Políticos, n. ${ }^{\circ}$ 35, 1983 , pp. 123-182. 
«Naturaleza y régimen legal de la suspensión general de los derechos fundamentales», Revista de Derecho Político, n. ${ }^{\circ} 18-19,1983$, pp. 31-58.

JANER Torrens, J. D., «La aplicación de la cláusula derogatoria del Convenio Europeo de Derechos Humanos con motivo de la crisis sanitaria derivada del COVID 19», Revista Electrónica de Estudios Internacionales, n. ${ }^{\circ}$ 40, 2020, pp. 1-28.

López Basaguren, A. y Maestro Buelga, G., «Garantismo, emergencia y suspensión de derechos fundamentales en la legislación de excepción», Revista Vasca de Administración Pública, n. ${ }^{\circ} 21,1988$, pp. 33-76.

MARín Aís, J. R., «El derecho de la Unión Europea ante las cláusulas derogatorias previstas en los tratados internacionales de derechos humanos», Revista de Derecho Comunitario Europeo, n. ${ }^{\circ}$ 66, 2020, pp. 519-557.

Requejo Rodríguez, P., «¿Suspensión o supresión de los derechos fundamentales?», Revista de Derecho Político, n. ${ }^{\circ}$ 51, 2001, pp. 105-138.

Roca Fernández, M. J., «La suspensión del Convenio Europeo de Derechos Humanos desde el Derecho español: procedimiento y control», Revista Española de Derecho Europeo, n. ${ }^{\circ}$ 72, 2019 , pp. 43-71.

Vírgala Foruria, E., «La suspensión de derechos por terrorismo en el ordenamiento español», Revista Española de Derecho Constitucional, n. ${ }^{\circ}$ 40, 1994, pp. 61-132.

\section{El impacto de la pandemia de la COVID-19 en los derechos fundamentales}

\section{Libros y capítulos de libros}

Bilbao Ubillos, J. M., «La libertad de reunión y manifestación en tiempos de pandemia», Biglino Campos, P. y Durán Alba, J. F. (dirs.), Los efectos horizontales de la Covid-19 sobre el sistema constitucional: estudios sobre la primera oleada, Colección Obras Colectivas, Fundación Manuel Giménez Abad, Zaragoza, 2021.

Carmona Cuenca, E., «Los derechos fundamentales en el estado de alarma. La crisis sanitaria de la COVID 19 en España», BARCEló Rojas, D., DíAz Ricci, S., GARCÍA Roca, J. y Guimaráes Teixeira Rocha, M. E., (coords.), COVID 19 y parlamentarismo. Los Parlamentos en cuarentena, Instituto de Investigaciones Jurídicas. Universidad Nacional Autónoma de México, México, 2020.

Cebrián Zazurca, E., «Pandemia y elecciones. El derecho de sufragio en España bajo las circunstancias excepcionales ocasionadas por la Covid-19», GARrido López, C. (coord.), Excepcionalidad y derecho: el estado de alarma en España, Colección Obras Colectivas, Fundación Manuel Giménez Abad, Zaragoza, 2021.

Celador Angón, O., «Libertad religiosa en la era COVID-19», Espejo Lerdo de Tejada, M., García Oliva, J., Martínez Cruz, J. y Murga Fernández, J. P. (dirs.) y Andrades Navarro, A. (coord.), Derecho y pandemia desde una perspectiva global, Thomson Reuters-Aranzadi, Cizur Menor, 2021.

Cidoncha Martín, A., "Coronavirus y libertad de empresa», Biglino Campos, P. y DurÁn AlBA, J. F. (dirs.), Los efectos horizontales de la Covid-19 sobre el sistema constitucional: estudios sobre la primera oleada, Colección Obras Colectivas, Fundación Manuel Giménez Abad, Zaragoza, 2021. 
Cierco Seira, C., «Derecho de la Salud Pública y COVID-19», Blanquer Criado, D. V. (coord.), COVID-19 y Derecho Público (durante el estado de alarma y más allá), Tirant Lo Blanch, Valencia, 2020.

Cobo del Rosal Pérez, G. (dir.) y Navalpotro Sánchez-Peinado, J. M., (ed. lit.), Derechos fundamentales en estado de alarma: una aproximación multidisciplinar, Dykinson, 2020.

Cotino Hueso, L., «La (in)constitucionalidad de las restricciones y suspensión de la libertad de circulación por el confinamiento frente a la COVID», GARRIDO LóPEZ, C. (coord.), Excepcionalidad y derecho: el estado de alarma en España, Colección Obras Colectivas, Fundación Manuel Giménez Abad, Zaragoza, 2021.

De Alba Bastarrechea, E., «La protección de datos durante la pandemia de COVID19», Arévalo Gutiérrez, A. (dir.) y Marañón Gómez, R. (coord.), El parlamento en los tiempos de la pandemia, Dykinson, Madrid, 2021.

De Montalvo JäÄskeläinen, F. y Bellver Capella, V., «La Bioética en los tiempos del coronavirus: una reflexión acerca de algunos dilemas éticos-legales de la pandemia a partir del Informe del Comité de Bioética de España», Atienza Macías, E. y Rodríguez Ayuso, J. F. (dirs.), Las respuestas del derecho a las crisis de salud pública, Dykinson, Madrid, 2020.

Delgado Del Rincón, L. E., «Algunas consideraciones sobre el derecho a la protección de la salud y el bien jurídico de la salud colectiva en tiempos de pandemia», BIGLINO Campos, P. y Durán AlBa, J. F. (dirs.), Los efectos horizontales de la Covid-19 sobre el sistema constitucional: estudios sobre la primera oleada, Colección Obras Colectivas, Fundación Manuel Giménez Abad, Zaragoza, 2021.

DueÑas Herrero, L. J., «El derecho al trabajo y las medidas laborales adoptadas para superar la crisis sanitaria y económica», Biglino Campos, P. y Durán Alba, J. F. (dirs.), Los efectos horizontales de la Covid-19 sobre el sistema constitucional: estudios sobre la primera oleada, Colección Obras Colectivas, Fundación Manuel Giménez Abad, Zaragoza, 2021.

Durán Alba, J. F., "Afectaciones a la libertad de circulación derivadas del estado de alarma declarado a causa de la crisis "covid-19" ", Biglino CAMPOS, P. y DuRÁN Alba, J. F. (dirs.), Los efectos horizontales de la Covid-19 sobre el sistema constitucional: estudios sobre la primera oleada, Colección Obras Colectivas, Fundación Manuel Giménez Abad, Zaragoza, 2021.

Gómez Puerto, Á. B., «Estado y medio ambiente en tiempo de pandemia», Dueñas Castrillo, A. I., Fernández Cañueto, D., Guerrero Vázquez, P. y Moreno GonzÁlez, G. (coords.), La Constitución en tiempos de pandemia, Dykinson, Madrid, 2021.

Guerrero Vázquez, P., «Estado de alarma sanitaria y medidas limitativas de la actividad económica», GARrido LóPEz, C. (coord.), Excepcionalidad y derecho: el estado de alarma en España, Colección Obras Colectivas, Fundación Manuel Giménez Abad, Zaragoza, 2021.

Macho Carro, A., "La afectación a la libre circulación de personas en la Unión Europea como consecuencia de las respuestas nacionales a la pandemia de COVID-19», Dueñas Castrillo, A. I., Fernández Cañueto, D., Guerrero Vázquez, P. y Moreno GonzÁlez, G. (coords.), La Constitución en tiempos de pandemia, Dykinson, Madrid, 2021. 
Martín Guardado, S., «Las libertades de reunión y manifestación en tiempos de la COVid-19», Dueñas Castrillo, A. I., Fernández Cañueto, D., Guerrero VÁzQuez, P. y Moreno González, G. (coords.), La Constitución en tiempos de pandemia, Dykinson, Madrid, 2021.

Martínez Cuevas, D., «Estados de alarma de 2010 y 2020 y las limitaciones sobre el derecho de huelga», GARrido López, C. (coord.), Excepcionalidad y derecho: el estado de alarma en España, Colección Obras Colectivas, Fundación Manuel Giménez Abad, Zaragoza, 2021.

Matia Portilla, F. J., «Covid e intimidad», Biglino Campos, P. y Durán Alba, J. F. (dirs.), Los efectos horizontales de la Covid-19 sobre el sistema constitucional: estudios sobre la primera oleada, Colección Obras Colectivas, Fundación Manuel Giménez Abad, Zaragoza, 2021.

Moretón Toquero, M. A., «Libertad de información y transparencia pública bajo el estado de alarma decretado para afrontar la pandemia por covid-19», BIGLINO CAMpos, P. y Durán Alba, J. F. (dirs.), Los efectos horizontales de la Covid-19 sobre el sistema constitucional: estudios sobre la primera oleada, Colección Obras Colectivas, Fundación Manuel Giménez Abad, Zaragoza, 2021.

Pérez Álvarez, S., «Restricciones a la libertad religiosa durante la crisis sanitaria del COVID-19», Atienza Macías, E. y Rodríguez Ayuso, J. F. (dirs.), Las respuestas del derecho a las crisis de salud pública, Dykinson, Madrid, 2020.

PiÑar MaÑas, J. L., «Transparencia y protección de datos en el estado de alarma y en la sociedad digital post COVID-19», Blanquer Criado, D. V. (coord.), COVID-19 y Derecho Público (durante el estado de alarma y más allá), Tirant Lo Blanch, Valencia, 2020.

Presno Linera, M. Á., «El derecho de reunión durante el estado de alarma sanitaria por Covid-19», GARrido López, C. (coord.), Excepcionalidad y derecho: el estado de alarma en España, Colección Obras Colectivas, Fundación Manuel Giménez Abad, Zaragoza, 2021.

Rey Martínez, F., «Pandemia y sistema educativo», Biglino Campos, P. y Durán AlBA, J. F. (dirs.), Los efectos horizontales de la Covid-19 sobre el sistema constitucional: estudios sobre la primera oleada, Colección Obras Colectivas, Fundación Manuel Giménez Abad, Zaragoza, 2021.

Riquelme Vázquez, P., «Elecciones en tiempos de pandemia: la experiencia de las Comunidades Autónomas de Galicia y el País Vasco», Dueñas Castrillo, A. I., Fernández Cañueto, D., Guerrero Vázquez, P. y Moreno González, G. (coords.), La Constitución en tiempos de pandemia, Dykinson, Madrid, 2021.

Rodríguez-Piñero y Bravo Ferrer, M., «Estado de alarma y derecho de manifestación del sindicato", Gómez MuÑoz, J. M. (ed.) y RodríGuez Ramos, M. J. (coord.), Nuevos escenarios del sistema de relaciones laborales derivados del COVID-19, Bomarzo, Albacete, 2021.

SÁNCHEZ MuÑoz, O., «El derecho de sufragio en tiempos de pandemia», Biglino CAMPos, P. y Durán Alba, J. F. (dirs.), Los efectos horizontales de la Covid-19 sobre el sistema constitucional: estudios sobre la primera oleada, Colección Obras Colectivas, Fundación Manuel Giménez Abad, Zaragoza, 2021.

SARrión Esteve, J., «Limitaciones a los derechos fundamentales en la declaración del estado de alarma para la gestión de la situación de crisis sanitaria ocasionada por el 
COVID-19», Atienza Macías, E. y Rodríguez Ayuso, J. F. (dirs.), Las respuestas del derecho a las crisis de salud pública, Dykinson, Madrid, 2020.

Simón YARZA, F., «Reflexiones sobre la libertad religiosa ante las restricciones impuestas como consecuencia del covid-19», Biglino Campos, P. y Durán Alba, J. F. (dirs.), Los efectos horizontales de la Covid-19 sobre el sistema constitucional: estudios sobre la primera oleada, Colección Obras Colectivas, Fundación Manuel Giménez Abad, Zaragoza, 2021.

Valverde Asencio, A. J., «El derecho a la protección y la salud en la empresa en una situación de pandemia», Gómez MuÑoz, J. M. (ed.) y Rodríguez Ramos, M. J. (coord.), Nuevos escenarios del sistema de relaciones laborales derivados del COVID-19, Bomarzo, Albacete, 2021.

Velasco Caballero, F., «Libertades públicas durante el estado de alarma por la COVID-19», Blanquer Criado, D. V. (coord.), COVID-19 y Derecho Público (durante el estado de alarma y más allá), Tirant Lo Blanch, Valencia, 2020.

VidAl Fueyo, M. C., «El derecho a la tutela judicial efectiva en tiempos de pandemia», Biglino Campos, P. y Durán AlBa, J. F. (dirs.), Los efectos horizontales de la Covid19 sobre el sistema constitucional: estudios sobre la primera oleada, Colección Obras Colectivas, Fundación Manuel Giménez Abad, Zaragoza, 2021.

Artículos de revistas

Alcubilla, E. A., «Salus populi est lex, sed lex superior est constitutio: El ejercicio del derecho de manifestación en el estado de alarma», Diario La Ley, n. ${ }^{\circ}$ 9645, 2020.

Cano Bueso, J., «La protección del derecho a la salud en tiempos de alarma sanitaria», Corts: Anuario de derecho parlamentario, n. ${ }^{\circ}$ extraordinario 34, 2021, pp. 175-202.

Cotino Hueso, L., «Confinamientos, libertad de circulación y personal, prohibición de reuniones y actividades y otras restricciones de derechos por la pandemia del coronavirus», Diario La Ley, n. ${ }^{\circ}$ 9606, 2020.

— «La enseñanza digital en serio y el derecho a la educación en tiempos del coronavirus», Revista de Educación y Derecho- Education and Law review, n. ${ }^{\circ}$ 21, 2020, pp. 1-29.

De Montalvo JäÄskeläinen, F. y Bellver Capella, V., «Priorizar sin discriminar: la doctrina del Comité de Bioética de España sobre derechos de las personas con discapacidad en un contexto de pandemia», IgualdadES, n. ${ }^{\circ}$ 3, 2020, pp. 313-341.

Ferrer Montenegro, A. y Oliú, A., «El derecho a la salud y su real ejercicio en los estados de emergencia», Revista de derecho, n. ${ }^{\circ}$ 5, 2003, pp. 211-224.

Gómez SANTOS, I. R., «El trabajo parlamentario para proteger la salud mental en tiempos de la COVID-19», Corts: Anuario de derecho parlamentario, n. ${ }^{\circ}$ extraordinario 34, 2021, pp. 59-80.

Ituren Oliver, A. y Esteve Segarra, A., «El derecho de huelga en tiempos del estado de alarma por el COVID 19», Trabajo y Derecho, n. ${ }^{\circ} 65$.

Leiva Escudero, G., «Constitucionalidad de las restricciones a la libertad de circulación en el estado de alarma por el coronavirus Covid-19», Diario La Ley, n. ${ }^{\circ}$ 9642, 2020.

Lepsius, O., «Protección de los derechos fundamentales en la pandemia del coronavirus», Teoría y Realidad Constitucional, n. ${ }^{\circ}$ 47, 2021, pp. 71-96. 
Marrades Puig, A. I., «Diseñando un nuevo modelo económico: propuestas desde el derecho constitucional y la economía feminista sobre el cuidado y la igualdad frente a la crisis COVID-19», IgualdadES, n. ${ }^{\circ}$ 3, 2020, pp. 379-402.

MARTín MARTínez, M. M., «Las restricciones a la libre circulación de personas en la UE durante la era COVID-19: hacia un futuro incierto», Araucaria. Revista Iberoamericana de Filosofía, Política, Humanidades y Relaciones Internacionales, n. ${ }^{\circ} 45,2020$, pp. 311-335.

Mercader Uguina, J. R., «El Big Data laboral: nuevos retos para la protección de datos en la era del cambio digital y el coronavirus», El Cronista del Estado Social y Democrático de Derecho, n. ${ }^{\circ} 88-89,2020$, pp. 126-135.

Nasarre Aznar, S., «Llueve sobre mojado: el problema del acceso a la vivienda en un contexto de pandemia», Derecho privado y Constitución, n. ${ }^{\circ}$ 37, 2020, pp. 273-308.

PÉrez Conchillo, E., «El derecho de acceso a la información pública en el marco del constitucionalismo multinivel y de la actual crisis sanitaria», Revista de Derecho Político, n. ${ }^{\circ} 109$, pp. 229-260.

— «evisión de la doctrina del TEDH sobre el derecho de acceso a la información pública en el contexto de la pandemia», Revista de Derecho Constitucional Europeo, n. ${ }^{\circ} 35,2021$.

Presno Linera, M. Á., «¿Ha sido España país para viejos durante la emergencia sanitaria de COVID-19?», IgualdadES, n. ${ }^{\circ}$ 3, 2020, pp. 275-312.

Rodríguez Ayuso, J. F., «Estado de alarma y protección de la privacidad en tiempos de pandemia: licitud del tratamiento de categorías especiales de datos», Revista de Derecho Político, n. ${ }^{\circ} 110,2021$, pp. 299-318.

RodrígueZ-Blanco, V., "¿Se vulneró el derecho a recibir información durante el primer estado de alarma en la crisis del COVID 19?», Revista Española de la Transparencia, n. ${ }^{\circ} 12,2021$, pp. 227-246.

Tenorio SÁnChez, P., «Cuarenta años de jurisprudencia constitucional en España: derecho a un recurso efectivo en relación con la declaración del estado de alarma como limitadora de derechos fundamentales», Anuario Iberoamericano de Justicia Constitucional, n. ${ }^{\circ}$ 25, 2021, pp. 195-223.

Teruel Lozano, G. M., «Vacunación universal, ¿pero obligatoria? Apuntes constitucionales en tiempos de pandemia», El notario del siglo XXI: revista del Colegio Notarial de Madrid, n. ${ }^{\circ}$ 95, 2021, pp. 18-23.

\section{FUNCIONAMIENTO DE LAS INSTITUCIONES Y DISTRIBUCIÓN TERRITORIAL DEL PODER POLÍTICO BAJO LA VIGENCIA DEL DERECHO DE EXCEPCIÓN}

\section{Libros y capitulos de libros}

Al Hasani Maturano, A., «La concentración del poder de dirección del ejecutivo en el período de pandemia», Dueñas Castrillo, A. I., Fernández Cañueto, D., Guerrero Vázquez, P. y Moreno GonzÁlez, G. (coords.), La Constitución en tiempos de pandemia, Dykinson, Madrid, 2021. 
Alcubilla, E. A., «El Tribunal Constitucional: el vigilante que debe vigilar», Recuerda Girela, M. Á. (coord.), Antes de la próxima pandemia, Thomson Reuters-Aranzadi, Cizur Menor, 2020.

Aragón Reyes, M., «COVID-19 y Estado autonómico», Tudela Aranda, J. (coord.), Estado autonómico y COVID-19: un ensayo de valoración general, Colección Obras colectivas, Fundación Manuel Giménez Abad, Zaragoza, 2021.

Arévalo Gutiérrez, A., «El Poder y la función legislativa en los tiempos del coronavirus», Arévalo Gutiérrez, A. (dir.) y Marañón Gómez, R. (coord.), El parlamento en los tiempos de la pandemia, Dykinson, Madrid, 2021.

- (dir.) y MARAÑón Gómez, R. (coord.), El parlamento en los tiempos de la pandemia, Dykinson, Madrid, 2021.

Balaguer Callejón, F., «La pandemia y el Estado autonómico», Tudela Aranda, J. (coord.), Estado autonómico y COVID-19: un ensayo de valoración general, Colección Obras colectivas, Fundación Manuel Giménez Abad, Zaragoza, 2021.

Barberà Aresté, O., «La crisis del COVID-19 y la aceleración de los procesos de transición digital en los partidos políticos», Reniu Vilamala J. M. y Meseguer SánCHEZ J. V. (dirs.), ¿Política confinada? Nuevas tecnologías y tomas de decisiones en un contexto de pandemia, Thomson Reuters-Aranzadi, Cizur Menor, 2020.

Barceló Rojas, D., Díaz Ricci, S., García Roca, J. y Guimaráes Teixeira Rocha, M. E., (coords.), COVID 19 y parlamentarismo. Los Parlamentos en cuarentena, Instituto de Investigaciones Jurídicas. Universidad Nacional Autónoma de México, México, 2020.

BARRAT i Esteve, J., «Actos personalísimos y utilización de nuevas tecnologías: a propósito del debate parlamentario», Reniu Vilamala J. M. y Meseguer Sánchez J. V. (dirs.), ¿Política confinada? Nuevas tecnologías y tomas de decisiones en un contexto de pandemia, Thomson Reuters-Aranzadi, Cizur Menor, 2020.

Biglino Campos, P., «El impacto de la COVID en la distribución de competencias», Tudela Aranda, J. (coord.), Estado autonómico y COVID-19: un ensayo de valoración general, Colección Obras colectivas, Fundación Manuel Giménez Abad, Zaragoza, 2021.

Carmona Contreras, A. M., «De la recentralización de competencias a su progresiva devolución a las Comunidades Autónomas durante el estado de alarma: las fases de desescalada», Tudela Aranda, J. (coord.), Estado autonómico y COVID-19: un ensayo de valoración general, Colección Obras colectivas, Fundación Manuel Giménez Abad, Zaragoza, 2021.

Cid Villagrasa, B., «La relación del Parlamento con los tribunales en tiempo de pandemia», Arévalo Gutiérrez, A. (dir.) y Marañón Gómez, R. (coord.), El parlamento en los tiempos de la pandemia, Dykinson, Madrid, 2021.

De la Quadra-Salcedo Janini, T., «Estado autonómico y lucha contra la pandemia», Biglino Campos, P. y Durán Alba, J. F. (dirs.), Los efectos horizontales de la Covid19 sobre el sistema constitucional: estudios sobre la primera oleada, Colección Obras Colectivas, Fundación Manuel Giménez Abad, Zaragoza, 2021.

Del Pino Carazo, A., «La actividad parlamentaria en tiempos de pandemia», Arévalo Gutiérrez, A. (dir.) y Marañón Gómez, R. (coord.), El parlamento en los tiempos de la pandemia, Dykinson, Madrid, 2021.

Dueñas Castrillo, A. I., «Las relaciones Parlamento-Gobierno durante el estado de alarma por covid-19», Biglino Campos, P. y Durán AlBa, J. F. (dirs.), Los efectos 
horizontales de la Covid-19 sobre el sistema constitucional: estudios sobre la primera oleada, Colección Obras Colectivas, Fundación Manuel Giménez Abad, Zaragoza, 2021.

FERnÁndez Esquer, C., «El impacto de la pandemia del COVID-19 en las elecciones: especial referencia al caso autonómico español», Palacios Romeo, F. y CEBrián ZAZURCA, E. (coords.), Elección y representación: una conjunción compleja. Perspectivas y problemas de los regímenes electorales en España, Colección Obras colectivas, Fundación Manuel Giménez Abad, Zaragoza, 2021.

Fernández Gutiérrez, M., «El Parlamento ante la COVID-19», Dueñas Castrillo, A. I., Fernández Cañueto, D., Guerrero Vázquez, P. y Moreno GonZÁLEZ, G. (coords.), La Constitución en tiempos de pandemia, Dykinson, Madrid, 2021.

FERNÁNDEZ Riveira, R. M., «El derecho de voto parlamentario ejercido de modo telemático en la crisis sanitaria del COVID-19», Reniu Vilamala J. M. y Meseguer SÁNCHez J. V. (dirs.), ¿Política confinada? Nuevas tecnologías y tomas de decisiones en un contexto de pandemia, Thomson Reuters-Aranzadi, Cizur Menor, 2020.

García RocA, J., «El control parlamentario y otros contrapesos del gobierno en el estado de alarma: la experiencia del coronavirus», BARCELó RojAs, D., Díaz RiCCI, S., García Roca, J. y Guimaráes Teixeira Rocha, M. E., (coords.), COVID 19 y parlamentarismo. Los Parlamentos en cuarentena, Instituto de Investigaciones Jurídicas. Universidad Nacional Autónoma de México, México, 2020.

García-Escudero Márquez P., «Actividad y funcionamiento de los Parlamentos españoles en la crisis sanitaria por COVID-19», BARCELó RojAs, D., DíAz RiCCI, S., García Roca, J. y Guimaráes Teixeira Rocha, M. E., (coords.), COVID 19 y parlamentarismo. Los Parlamentos en cuarentena, Instituto de Investigaciones Jurídicas. Universidad Nacional Autónoma de México, México, 2020.

—Crisis sanitaria y modelo autonómico», Tudela Aranda, J. (coord.), Estado autonómico y COVID-19: un ensayo de valoración general, Colección Obras colectivas, Fundación Manuel Giménez Abad, Zaragoza, 2021.

Guerrero VÁzquez, P., «El impacto territorial de la crisis sanitaria», Tudela ARANDA, J. (coord.), Estado autonómico y COVID-19: un ensayo de valoración general, Colección Obras colectivas, Fundación Manuel Giménez Abad, Zaragoza, 2021.

Herbón Costas, J. J., «El mando y gestión del estado de alarma», Biglino Campos, P. y Durán Alba, J. F. (dirs.), Los efectos horizontales de la Covid-19 sobre el sistema constitucional: estudios sobre la primera oleada, Colección Obras Colectivas, Fundación Manuel Giménez Abad, Zaragoza, 2021.

Jover Gómez-Ferrer, J. M., «El Gobierno: lecciones de una crisis», Recuerda Girela, M. Á. (coord.), Antes de la próxima pandemia, Thomson Reuters-Aranzadi, Cizur Menor, 2020.

Krimmer, R. y DueÑas Cid, D., «Prólogo. Tecnología y democracia: ¿un amor de pandemia o una relación estable?» en Reniu Vilamala J. M. y Meseguer SánChez J. V. (dirs.), ¿Política confinada? Nuevas tecnologías y tomas de decisiones en un contexto de pandemia, Thomson Reuters-Aranzadi, Cizur Menor, 2020.

Lucio Gil, A., «Comisiones de investigación y pandemia», Arévalo Gutiérrez, A (dir.) y Marañón Gómez, R. (coord.), El parlamento en los tiempos de la pandemia, Dykinson, Madrid, 2021.

Marañón Gómez, R., «Distancia social en el Parlamento. Aforos reducidos y voto telemático: panorámica comparada y experiencia de la Asamblea de Madrid», ArÉvalo 
Gutiérrez, A. (dir.) y Marañón Gómez, R. (coord.), El parlamento en los tiempos de la pandemia, Dykinson, Madrid, 2021.

Marazuela Bermejo, A., «La tecnología contra el COVID en el ámbito parlamentario», Arévalo Gutiérrez, A. (dir.) y Marañón Gómez, R. (coord.), El parlamento en los tiempos de la pandemia, Dykinson, Madrid, 2021.

Martínez Dalmau, R., «Los desafíos del uso de las nuevas tecnologías en los órganos colegiados: acerca de las actualizaciones de urgencia en el marco de una situación de crisis», Reniu Vilamala J. M. y Meseguer Sánchez J. V. (dirs.), ¿Política confinada? Nuevas tecnologías y tomas de decisiones en un contexto de pandemia, Thomson Reuters-Aranzadi, Cizur Menor, 2020.

Matia Portilla, F. J., «Ensayo de aproximación a las cuestiones planteadas por la crisis sanitaria en relación con el Estado autonómico», Tudela Aranda, J. (coord.), Estado autonómico y COVID-19: un ensayo de valoración general, Colección Obras colectivas, Fundación Manuel Giménez Abad, Zaragoza, 2021.

Montero Caro, M. D., «La cooperación entre el gobierno central y los gobiernos autonómicos ante la pandemia del COVID-19», Dueñas Castrillo, A. I., Fernández Cañueto, D., Guerrero Vázquez, P. y Moreno GonzÁlez, G. (coords.), La Constitución en tiempos de pandemia, Dykinson, Madrid, 2021.

Ortea García, E., Cortes Generales y emergencia sanitaria: labor parlamentaria en un contexto distópico. Una panorámica de la adaptación práctica del Derecho Parlamentario español a la crisis de la COVID-19, Colección Estudios 8, Fundación Manuel Giménez Abad, Zaragoza, 2021.

Panizo Alonso, L. y Marcos del Blanco, D. Y., «La ciberseguridad en los procesos democráticos», Reniu Vilamala J. M. y Meseguer Sánchez J. V. (dirs.), ¿Política confinada? Nuevas tecnologías y tomas de decisiones en un contexto de pandemia, Thomson Reuters-Aranzadi, Cizur Menor, 2020.

PeÑa López, I., «El ecosistema de gobernanza pública: las instituciones como infraestructuras abiertas para la toma de decisiones colectivas», Reniu Vilamala J. M. y Meseguer SÁnchez J. V. (dirs.), ¿Politica confinada? Nuevas tecnologías y tomas de decisiones en un contexto de pandemia, Thomson Reuters-Aranzadi, Cizur Menor, 2020.

RECUERDA Girela, M. Á., «Los poderes públicos: anormalidad y parálisis en el Estado de Derecho», Recuerda Girela, M. Á. (coord.), Antes de la próxima pandemia, Thomson Reuters-Aranzadi, Cizur Menor, 2020.

Reniu Vilamala J. M. y Meseguer Sánchez J. V. (dirs.), ¿Política confinada? Nuevas tecnologias y tomas de decisiones en un contexto de pandemia, Thomson Reuters-Aranzadi, Cizur Menor, 2020.

Reniu Vilamala J. M., «La gestión de un escenario imprevisible: ¿confinar la política?», Reniu Vilamala J. M. y Meseguer Sánchez J. V. (dirs.), ¿Política confinada? Nuevas tecnologías y tomas de decisiones en un contexto de pandemia, Thomson Reuters-Aranzadi, Cizur Menor, 2020.

Revuelta de Rojas, I. y Pendás Prieto, P., «Las Cortes Generales: el centro y eje de la vida política en el estado constitucional», ReCuerda Girela, M. Á. (coord.), Antes de la próxima pandemia, Thomson Reuters-Aranzadi, Cizur Menor, 2020.

RIDAO, J., Derecho de crisis y Estado autonómico. Del estado de alarma a la cogobernanza en la gestión de la COVID-19, Marcial Pons, Madrid, 2021. 
Rodríguez-PÉrez, A. y Puiggalí, J., «Con el voto (telemático) no es suficiente: herramientas digitales para el funcionamiento remoto de parlamentos y asambleas», Reniu Vilamala J. M. y Meseguer Sánchez J. V. (dirs.), ¿Política confinada? Nuevas tecnologías y tomas de decisiones en un contexto de pandemia, Thomson Reuters-Aranzadi, Cizur Menor, 2020.

Rubio, R. y Gonzalo Rozas, M. Á., «Presencialidad y excepcionalidad en el parlamento en tiempos de pandemia global», Reniu Vilamala J. M. y Meseguer SánCHEZ J. V. (dirs.), ¿Politica confinada? Nuevas tecnologías y tomas de decisiones en un contexto de pandemia, Thomson Reuters-Aranzadi, Cizur Menor, 2020.

SÁNCHEZ Navarro, Á. J., «Emergencia sanitaria y suspensión de elecciones», BARCEló Rojas, D., Díaz Ricci, S., García Roca, J. y Guimaráes Teixeira Rocha, M. E., (coords.), COVID 19 y parlamentarismo. Los Parlamentos en cuarentena, Instituto de Investigaciones Jurídicas. Universidad Nacional Autónoma de México, México, 2020.

Santamaría Pastor, J. A., «Notas sobre el ejercicio de las potestades normativas en tiempos de pandemia», Blanquer Criado, D. V. (coord.), COVID-19 y Derecho Público (durante el estado de alarma y más allá), Tirant Lo Blanch, Valencia, 2020.

SAnz Moreno, J. A., «Democracia en pandemia: comunicación, redes y populismo», Reniu Vilamala J. M. y Meseguer Sánchez J. V. (dirs.), ¿Política confinada? Nuevas tecnologías y tomas de decisiones en un contexto de pandemia, Thomson Reuters-Aranzadi, Cizur Menor, 2020.

SiERra Rodríguez, J., «Estado de alarma, transparencia gubernamental y rendición de cuentas durante la crisis del COVID-19», Reniu Vilamala J. M. y Meseguer SÁnchez J. V. (dirs.), ¿Política confinada? Nuevas tecnologías y tomas de decisiones en un contexto de pandemia, Thomson Reuters-Aranzadi, Cizur Menor, 2020.

Solozábal Echavarría, J. J., «La crisis del coronavirus tras el primer estado de alarma», Tudela ArAnda, J. (coord.), Estado autonómico y COVID-19: un ensayo de valoración general, Colección Obras colectivas, Fundación Manuel Giménez Abad, Zaragoza, 2021.

Tudela Aranda, J. (coord.), Estado autonómico y COVID-19: un ensayo de valoración general, Colección Obras colectivas, Fundación Manuel Giménez Abad, Zaragoza, 2021.

- «El Estado autonómico y la COVID-19», Tudela Aranda, J. (coord.), Estado autonómico y COVID-19: un ensayo de valoración general, Colección Obras colectivas, Fundación Manuel Giménez Abad, Zaragoza, 2021.

—Parlamento y estado de alarma», GARrido López, C. (coord.), Excepcionalidad $y$ derecho: el estado de alarma en España, Colección Obras Colectivas, Fundación Manuel Giménez Abad, Zaragoza, 2021.

Ubasart GonzÁlez, G., «Ciudadanía virtual en tiempos de pandemia: activismo, acción comunitaria e iniciativas culturales», Reniu Vilamala J. M. y Meseguer SÁNCHEZ J. V. (dirs.), ¿Política confinada? Nuevas tecnologías y tomas de decisiones en un contexto de pandemia, Thomson Reuters-Aranzadi, Cizur Menor, 2020.

Vela Navarro-Rubio, R., «La adaptación de los parlamentos autonómicos a la crisis del COVID-19», Reniu Vilamala J. M. y Meseguer Sánchez J. V. (dirs.), ¿Política confinada? Nuevas tecnologías y tomas de decisiones en un contexto de pandemia, Thomson Reuters-Aranzadi, Cizur Menor, 2020. 
VIDAl Prado, C., «La celebración de elecciones: una solución controvertida», RECUERDA Girela, M. Á. (coord.), Antes de la próxima pandemia, Thomson Reuters-Aranzadi, Cizur Menor, 2020.

Artículos de revistas

Abellán Artacho, P., «Sobre el control parlamentario al Gobierno Central y a los Gobiernos Autonómicos durante la crisis del coronavirus», Cuadernos Manuel Giménez Abad, n. ${ }^{\circ}$ 19, 2020, pp. 122-134.

Alonso Prado, V. E., «El control del Congreso de los Diputados al Gobierno y la actividad parlamentaria durante el estado de alarma», Gabilex: Revista del Gabinete Jurídico de Castilla-La Mancha, n. ${ }^{\circ}$ 21, 2020, pp. 73-108.

AzPitarte SÁnCHez, M., «Coronavirus y Derecho Constitucional. Crónica política y legislativa del año 2020», Revista Española de Derecho Constitucional, n. ${ }^{\circ} 121,2021$, pp. $105-138$.

Blanes Climent, M. Á., «La incidencia del COVID-19 sobre la transparencia de las instituciones públicas», Revista Española de la Transparencia, n. ${ }^{\circ} 11,2020$, pp. 13-20.

Cabedo Laborda, C., «El ejercicio del voto parlamentario telemático en las Corts Valencianes durante la pandemia de COVID-19», Corts: Anuario de derecho parlamentario, n. ${ }^{\circ}$ extraordinario 34, 2021, pp. 41-58.

Carmona Contreras, A. M., «El estado autonómico y la gestión jurídica de la pandemia», Cuadernos Manuel Giménez Abad, n. . 21, 2021, p. 37-53.

Carrasco Durán, M., «El Parlamento ante la pandemia de la COVID-19: el caso del Parlamento de Andalucía», Cuadernos Manuel Giménez Abad, n. ${ }^{\circ}$ extraordinario 8, 2020, pp. 28-36.

—El Parlamento en los tiempos del coronavirus: el recurso a la Diputación Permanente», Revista Española de Derecho Constitucional, n. ${ }^{\circ}$ 122, 2021, pp. 119-150.

Fernández de Gatta SÁnChez, D., «Auto del Tribunal Constitucional 40/2020, de 30 de abril, y Sentencias y Autos del Tribunal Supremo y otros Tribunales. El control constitucional y judicial del estado de alarma por la epidemia del coronavirus», Ars Iuris Salmanticensis, n. ${ }^{\circ}$ 8, 2020, pp. 313-324.

Fernández de Simón Bermejo, E., «La actuación de la Asamblea Regional de Murcia desde la declaración del estado de alarma por la crisis sanitaria provocada por el COVID19», Cuadernos Manuel Giménez Abad, n. extraordinario 8, 2020, pp. 147-154.

Fernández Gutiérrez, M., «La Junta General del Principado de Asturias bajo la pandemia ocasionada por la COVID-19», Cuadernos Manuel Giménez Abad, n. ${ }^{\circ}$ extraordinario 8, 2020, pp. 53-65.

García de Enterría Ramos, A. y Navarro Mejía, I., «La actuación de las Cortes Generales durante el estado de alarma para la gestión de la crisis del COVID-19», Revista de las Cortes Generales, n. ${ }^{\circ}$ 108, 2020, pp. 245-288.

García-Escudero Márquez, P., «Actividad y funcionamiento de las Cortes Generales durante el estado de alarma por COVID-19», Cuadernos Manuel Giménez Abad, n. ${ }^{\circ}$ extraordinario 8, 2020, pp. 18-27.

García Mengual, F., «Les noves tecnologíes en l'activitat no presencial dels membres del parlament: l'experiència de les Corts Valencianes durant la pandèmia de la 
COVID-19», Corts: Anuario de derecho parlamentario, n. ${ }^{\circ}$ extraordinario 34, 2021, pp. 97-116.

Garrido MAYOL, V., «La COVID-19 también llegó al parlamento: la excepcionalidad como excusa del Estado de Derecho», Corts: Anuario de derecho parlamentario, n. ${ }^{\circ}$ extraordinario 34, 2021, pp. 139-174.

Greciet García, E., «La Asamblea de Madrid y el COVID-19: lo que nunca debió suceder», Cuadernos Manuel Giménez Abad, n. ${ }^{\circ}$ extraordinario 8, 2020, pp. 115-146.

Guillem Carrau, J., «La participación de los 'millenials' y la generación Z: una nueva oportunidad para el voto por Internet y para el legislador autonómico en tiempos de pandemia», Corts: Anuario de derecho parlamentario, n. ${ }^{\circ}$ extraordinario 34, 2021, pp. $255-278$.

Iturbe MaCH, A., «El Parlamento Vasco en tiempos virulentos. Una crónica desapasionada y un colofón», Cuadernos Manuel Giménez Abad, n. ${ }^{\circ}$ extraordinario 8, 2020, pp. 94-103.

KöLling, M., «Federalism and the COVID-19 crisis: a perspective from Spain», Cuadernos Manuel Giménez Abad, n. ${ }^{\circ}$ 19, 2020, pp. 41-43.

Lasagabaster Herrarte, I., «La respuesta a la pandemia del Covid-19 y el estado de las autonomías», Eunomía, Revista en Cultura de la Legalidad, n. ${ }^{\circ}$ 19, 2020, pp. 127-153.

León Alonso, M., «Sentencia del Tribunal Constitucional 83/2016, de 28 de abril de 2016. Control jurisdiccional exclusivo del Tribunal Constitucional de los actos gubernamentales y parlamentarios de declaración, autorización y prórroga de los estados de alarma», Ars Iuris Salmanticensis, n. ${ }^{\circ}$ 4, 2016, pp. 234-237.

López Guerra, L., «Los efectos de la pandemia sobre la evolución del Estado social en España», Teoría y Derecho. Revista de pensamiento jurídico, n. . 28, 2020, pp. 38-53.

López Picó, C., «"A vueltas” con la descentralización educativa. La experiencia en tiempos de Covid-19», Cuadernos Manuel Giménez Abad, n. ${ }^{\circ}$ 21, 2021, p. 54-60.

Maluenda Verdú, R., «Les Corts y la crisis sanitaria», Corts: Anuario de derecho parlamentario, n. ${ }^{\circ}$ extraordinario 34, 2021, pp. 81-96.

Martínez Corral, J. A., «Les Corts Valencianes y el coronavirus COVID-19», Cuadernos Manuel Giménez Abad, n. ${ }^{\circ}$ extraordinario 8, 2020, pp. 165-188.

Matia Portilla, E., «La COVID-19 y las Cortes de Castilla y León», Cuadernos Manuel Giménez Abad, n. ${ }^{\circ}$ extraordinario 8, 2020, pp. 66-75.

Nieto Jiménez, J. C., «Parlamento y crisis sanitaria. Análisis constitucional de la resolución de la presidencia del Parlamento de Andalucía "sobre habilitación de la convocatoria de la Diputación Permanente en una situación de declaración de Estado de alarma"», Cuadernos Manuel Giménez Abad, n. ${ }^{\circ} 20,2020$, pp. 253-270.

Pérez-Cruz Martín, A. J., «El control jurisdiccional de la declaración del estado de alarma y sus prórrogas», Revista General de Derecho Procesal, n. ${ }^{\circ}$ 52, 2020.

Porras Nadales, A., «El Estado Social sometido a prueba», Revista Asuntos Constitucionales, $\mathrm{n}^{\circ}{ }^{\mathrm{O}} 1,2021$.

Pulido Quecedo, M. y Laurenz Itoiz, M. Á., «La respuesta del Parlamento de Navarra a la crisis provocada por el COVID-19», Cuadernos Manuel Giménez Abad, n. ${ }^{\circ}$ extraordinario 8,2020 , pp. 155-164.

RIDAO, J., «La pugna sobre la prevalencia del estado de alarma o de los poderes de necesidad de la legislación sanitaria como expresión de las diferencias sobre el estado 
autonómico. Un debate más allá de la controversia entre el formalismo constitucionalista defensor de los derechos fundamentales y el pragmatismo administrativista», El Cronista del Estado Social y Democrático de Derecho, n. ${ }^{\circ} 95,2021$, pp. 40-51.

— «irtualizando el Parlamento (hasta donde se puede). El régimen de contingencia del Parlamento de Cataluña durante la crisis de la COVID-19 y las reformas tecnológicas y reglamentarias operadas para regular la actividad no presencial en el futuro», Cuadernos Manuel Giménez Abad, n. ${ }^{\circ}$ extraordinario 8, 2020, pp. 76-93.

Ripollés SERrano, M. R., «¿Un parlamento por delegación? La experiencia de una comisión permanente del Congreso de los Diputados durante la pandemia por la COVID-19», Corts: Anuario de derecho parlamentario, n. ${ }^{\circ}$ extraordinario 34, 2021, pp. 203-224.

Rubio de Val, C. y Blasco Jáuregui, J., «El papel del Parlamento autonómico en el estado de alarma. Crónica de la actividad de las Cortes de Aragón (marzo-mayo 2020)», Cuadernos Manuel Giménez Abad, n. ${ }^{\circ}$ extraordinario 8, 2020, pp. 37-52.

Rubio NúÑEz, R., "La tecnología en el Parlamento durante la crisis del COVID-19», Cuadernos Manuel Giménez Abad, n. ${ }^{\circ}$ extraordinario 8, 2020, pp. 226-236.

SAlvador Rubert, M. J., "Preservar l'activitat parlamentària en temps de COVID19», Corts: Anuario de derecho parlamentario, n. ${ }^{\circ}$ extraordinario 34, 2021, pp. 19-40.

SANAHUJA, J. A., "COVID-19: riesgo, pandemia y crisis de gobernanza global», Anuario CEIPAZ 2019-2020. Riesgos globales y multilateralismo: el impacto de la COVID-19, 2020, pp. 27-54.

Sarmiento Méndez, X. A., «COVID-19: Una visión desde el Parlamento de Galicia y su administración electoral», Corts: Anuario de derecho parlamentario, n. ${ }^{\circ}$ extraordinario 34, 2021, pp. 225-254.

—La reacción del Parlamento de Galicia ante la crisis sanitaria. ¿Puede la Diputación Permanente ejercer «otras funciones» en una cámara disuelta?», Cuadernos Manuel Giménez Abad, n. ${ }^{\circ}$ extraordinario 8, 2020, pp. 104-114.

Tudela Aranda, J., «Parlamento y crisis sanitaria. Reflexiones preliminares», Cuadernos Manuel Giménez Abad, n. ${ }^{\circ}$ extraordinario 8, 2020, pp. 6-17.

Velasco Caballero, F., «Derecho local y COVID-19», Revista Galega De Administración Pública, n. ${ }^{\circ}$ 59, 2020, pp. 237-266.

— «stado de alarma y distribución territorial del poder», El Cronista del Estado Social y Democrático de Derecho, n. ${ }^{\circ} 86-87,2020$, pp. 78-87.

\section{EL DERECHO DE EXCEPCIÓN EN CLAVE INTERNACIONAL Y COMPARADA}

Libros y capítulos de libros

Alcaraz, H., «El estado de emergencia sanitaria en Francia: ¿Elogio de la excepción?», Biglino Campos, P. y Durán Alba, J. F. (dirs.), Los efectos horizontales de la Covid19 sobre el sistema constitucional: estudios sobre la primera oleada, Colección Obras Colectivas, Fundación Manuel Giménez Abad, Zaragoza, 2021.

Aranda Álvarez, E., Los efectos de la crisis del COVID-19 en el Derecho Constitucional económico de la Unión Europea. Una oportunidad para repensar la relación entre estabilidad 
presupuestaria y gasto público, Colección Debates Constitucionales, Marcial Pons, 2021.

Barroso Márquez, J. F., «Estado de Derecho, iliberalismo y poderes de emergencia: oportunismo político en Hungría», Dueñas Castrillo, A. I., Fernández Cañueto, D., Guerrero Vázquez, P. y Moreno González, G. (coords.), La Constitución en tiempos de pandemia, Dykinson, Madrid, 2021.

Camoni Rodríguez, D., "COVID-19 y fuentes del Derecho en Italia: una complicada perspectiva de Derecho Constitucional», Dueñas Castrillo, A. I., Fernández Cañueto, D., Guerrero Vázquez, P. y Moreno GonzÁlez, G. (coords.), La Constitución en tiempos de pandemia, Dykinson, Madrid, 2021.

Castellà Andreu, J. M., «La Comisión de Venecia y los estados de emergencia. La necesaria preservación del Estado de Derecho y la democracia constitucional durante la crisis de la Covid-19», Biglino Campos, P. y Durán Alba, J. F. (dirs.), Los efectos horizontales de la Covid-19 sobre el sistema constitucional: estudios sobre la primera oleada, Colección Obras Colectivas, Fundación Manuel Giménez Abad, Zaragoza, 2021.

Ferrer Mac-Gregor, E., «Restricción y suspensión de derechos en los tiempos del coronavirus (reflexiones a partir de la jurisprudencia interamericana)», BARCELÓ Rojas, D., Díaz Ricci, S., García Roca, J. y Guimaráes Teixeira Rocha, M. E., (coords.), COVID 19 y parlamentarismo. Los Parlamentos en cuarentena, Instituto de Investigaciones Jurídicas. Universidad Nacional Autónoma de México, México, 2020.

García Ortiz, A., «La pandemia del COVID-19: lecciones para la Unión Europea en perspectiva constitucional», Dueñas Castrillo, A. I., Fernández Cañueto, D., Guerrero Vázquez, P. y Moreno GonzÁlez, G. (coords.), La Constitución en tiempos de pandemia, Dykinson, Madrid, 2021.

Gómez MuÑoz, J. M., «La acción de la Unión Europea durante la pandemia de SARSCOV-2», Gómez MuÑoz, J. M. (ed.) y Rodríguez Ramos, M. J. (coord.), Nuevos escenarios del sistema de relaciones laborales derivados del COVID-19, Bomarzo, Albacete, 2021.

KöLliNG, M., «Las instituciones democráticas y los derechos fundamentales en tiempos de Covid-19 en Alemania», Biglino Campos, P. y Durán Alba, J. F. (dirs.), Los efectos horizontales de la Covid-19 sobre el sistema constitucional: estudios sobre la primera oleada, Colección Obras Colectivas, Fundación Manuel Giménez Abad, Zaragoza, 2021.

— «Una perspectiva desde el federalismo alemán», Tudela Aranda, J. (coord.), Estado autonómico y COVID-19: un ensayo de valoración general, Colección Obras colectivas, Fundación Manuel Giménez Abad, Zaragoza, 2021

Macho Carro, A., «La intervención de la UE frente a las consecuencias económicas de la pandemia de la covid-19 y su articulación jurídica», Biglino CAMPOS, P. y Durán Alba, J. F. (dirs.), Los efectos horizontales de la Covid-19 sobre el sistema constitucional: estudios sobre la primera oleada, Colección Obras Colectivas, Fundación Manuel Giménez Abad, Zaragoza, 2021.

Martínez Cuevas, D., «La suspensión de derechos y libertades por terrorismo en el Reino Unido, Italia, Francia, Alemania y España: su incorporación a la legislación ordinaria con carácter permanente», Zugaldía EsPINAR J. M., Roca RocA, E. y 
Portero García, L. (coords.), Los derechos humanos: libro homenaje al Excmo. Sr. D. Luis Portero García, Universidad de Granada, Granada, 2001.

Mastromarino, A., «La respuesta a la emergencia Covid-19: el caso italiano», Biglino Campos, P. y Durán AlBa, J. F. (dirs.), Los efectos horizontales de la Covid-19 sobre el sistema constitucional: estudios sobre la primera oleada, Colección Obras Colectivas, Fundación Manuel Giménez Abad, Zaragoza, 2021.

Meseguer SÁnchez, J. V., «La crisis de la COVID-19 como aceleradora del proceso de construcción europea», Reniu Vilamala J. M. y Meseguer SánChez J. V. (dirs.), ¿Política confinada? Nuevas tecnologías y tomas de decisiones en un contexto de pandemia, Thomson Reuters-Aranzadi, Cizur Menor, 2020.

Passaglia, P., «La incidencia de la pandemia COVID-19 en los sistemas constitucionales europeos», Aragón Reyes, M., Cossío Díaz, J. R. y Nava Gomar, L. F. (coords.), La crisis del parlamentarismo en nuestra democracia constitucional, Tirant Lo Blanch, Valencia, 2021.

PÉrez GonzÁlez, C., «El Derecho Internacional de los Derechos Humanos ante las crisis sanitarias: principios aplicables y obligaciones de los Estados», AtienZA MAcías, E. y Rodríguez Ayuso, J. F. (dirs.), Las respuestas del derecho a las crisis de salud pública, Dykinson, Madrid, 2020.

Romboli, R., «La incidencia de la pandemia del Coronavirus en el sistema constitucional italiano», Aragón Reyes, M., Cossío Díaz, J. R. y Nava Gomar, L. F. (coords.), La crisis del parlamentarismo en nuestra democracia constitucional, Tirant Lo Blanch, Valencia, 2021.

SÁNCHEZ FERro, S., «La respuesta británica frente a la crisis desatada por la Covid-19», Biglino Campos, P. y Durán Alba, J. F. (dirs.), Los efectos horizontales de la Covid19 sobre el sistema constitucional: estudios sobre la primera oleada, Colección Obras Colectivas, Fundación Manuel Giménez Abad, Zaragoza, 2021.

Santamaría Dacal, A. I., «COVID y Derecho público en Francia: un «estado de urgencia sanitario» bajo control judicial», Blanquer CRIADO, D. V. (coord.), COVID-19 y Derecho Público (durante el estado de alarma y más allá), Tirant Lo Blanch, Valencia, 2020.

SuÑé CANO, J. E., «Una reflexión a la sombra de la crisis del covid-19 sobre la necesidad de adoptar la Declaración Universal de Derechos Humanos como constitución global», Cobo del Rosal Pérez, G. (dir.) y Navalpotro Sánchez-Peinado, J. M., (ed. lit.), Derechos fundamentales en estado de alarma: una aproximación multidisciplinar, Dykinson, 2020.

VALADÉs, D., «La incidencia de la pandemia del Coronavirus en el sistema constitucional mexicano», Aragón Reyes, M., Cossío Díaz, J. R. y Nava Gomar, L. F. (coords.), La crisis del parlamentarismo en nuestra democracia constitucional, Tirant Lo Blanch, Valencia, 2021.

Artículos de revistas

Adamo, U., «Medidas de emergencia epidémica y métodos de adopción: cuestiones constitucionales e impactos en el ordenamiento italiano», Revista de Derecho Constitucional Europeo, n. ${ }^{\circ}$ 35, 2021. 
Barceló, D., «Covid-19 y sistema federal mexicano», Cuadernos Manuel Giménez Abad, n. ${ }^{\circ}$ 20, 2020, pp. 67-70.

BArroso Márquez, J. F., «Estado de Derecho e igualdad: poder ejecutivo «ilimitado» como respuesta a la crisis de la COVID-19 y vulneración de los derechos LGTBI en Hungría y Polonia», IgualdadES, n. ${ }^{\circ}$, pp.183-214.

Cameron, D., «La gestión de la pandemia en países federales y no federales», Cuadernos Manuel Giménez Abad, n. ${ }^{\circ} 21,2021$, pp. 7-23.

Castellà Andreu, J. M., "Compilación de la Comisión de Venecia de opiniones e informes sobre estados de emergencia», Revista General de Derecho Constitucional, n. ${ }^{\circ} 32,2020$, pp. 1-7.

Cerdé Guzmán, C., «Los derechos fundamentales y la lucha contra el terrorismo: Francia bajo estado de emergencia», Revista de Derecho constitucional europeo, n. ${ }^{\circ}$ 27, 2017.

Cervantes, A., Matarrita, M. y Reca, S., «Los estados de excepción en tiempos de pandemia. Un estudio comparado en América Latina», Cuadernos Manuel Giménez Abad, n. ${ }^{\circ}$ 20, 2020, pp. 179-206.

Dani, M. y MenÉndez, A. J., «El gobierno europeo de la crisis del coronavirus», Revista de Derecho constitucional europeo, n. $^{\circ} 34,2020$.

De la Sierra Morón, S., «Lectura de urgencia de las reacciones frente al COVID-19 desde una óptica jurídica internacional y comparada», El Cronista del Estado Social y Democrático de Derecho, n. ${ }^{\circ} 86-87,2020$, pp. 32-41.

Domínguez Zorrero, M., «Estados excepcionales y garantía de derechos fundamentales en Latinoamérica», Revista de Estudios Políticos, n. ${ }^{\circ}$ 81, 1993, pp. 265-276.

FAGGIANI, V., «Los estados de excepción ante los nuevos desafíos: hacia una sistematización en perspectiva multinivel», federalismi.it Rivista di Diritto Pubblico Italiano, Comparato, Europeo, n. ${ }^{\circ} 24,2020$, pp. 18-43.

—Los estados de excepción. Perspectivas desde el derecho constitucional europeo», Revista de Derecho Constitucional Europeo, n. ${ }^{\circ}$ 17, 2012, pp. 181-231.

Goig Martínez, J. M., «La defensa política de la Constitución. Constitución y estados excepcionales (II). Un estudio de Derecho Constitucional comparado», Revista de Derecho UNED, n. ${ }^{\circ}$ 5, 2009, pp. 211-251.

Guerrero VÁzQuez, P., «El sistema parlamentario británico ante la COVID-19», Cuadernos Manuel Giménez Abad, n. ${ }^{\circ}$ extraordinario 8, 2020, pp. 200-215.

HäBerle, P. y Kotzur, M., «La pandemia del COVID-19 analizada desde la perspectiva científico-cultural de una teoría constitucional europea y universal», Revista de Derecho Constitucional Europeo, n. ${ }^{\circ}$ 35, 2021.

Kölling, M., «El Bundestag y el Bundesrat alemán en tiempos de COVID-19», Cuadernos Manuel Giménez Abad, n. ${ }^{\circ}$ extraordinario 8, 2020, pp. 189-199.

$$
* * *
$$

TITLE: Bibliographic repertory on spanish emergency law in constitutional perspective

ABSTRACT: This bibliographic repertory classifies the publications that analyse the constitutional dimensions of emergency law in Spain into four main categories. The first group includes studies on states of emergency in the Spanish legal system, with a specific section on their application in the health crisis caused by the COVID-19 pandemic. The second group brings together books, book chapters and articles on the impact of fundamental rights in times of constitutional emergency. The third category focuses on the functioning of 
institutions and the territorial distribution of political power under law of exception. The final list of publications offers an international and comparative overview that enhances the legal analysis of situations of constitutional exceptionality.

RESUMEN: El presente repertorio bibliográfico clasifica en cuatro grandes categorias las publicaciones que analizan las dimensiones constitucionales del derecho de excepción en España. El primer grupo engloba aquellas obras que estudian los estados de emergencia en el ordenamiento jurídico español, destinando un apartado específico a las investigaciones que bacen balance de su aplicación en el contexto de la crisis sanitaria provocada por la pandemia de la COVID-19. El segundo recoge los libros, capítulos de libro y artículos que versan sobre la afectación de los derechos fundamentales en tiempos de emergencia constitucional. La tercera categoría aborda el funcionamiento de las instituciones y la distribución territorial del poder político bajo la vigencia del derecho de excepción. Por último, el elenco final de publicaciones ofrece una mirada internacional y comparada que enriquece el análisis jurídico de las situaciones de excepcionalidad constitucional.

KEY WORDS: the law of exception, constitutional emergency, health crisis, fundamental rights.

PALABRAS ClAVE: derecho de excepción, emergencia constitucional, crisis sanitaria, derechos fundamentales.

FECHA DE RECEPCIÓN: 13.09.2021

FeCHa de ACEPTACión: 08.10.2021 
